\title{
Article
}

\section{Short intramolecular $0 . . .0$ contact in some 0-dialkoxybenzene derivatives generates efficient hydrogen bonding acceptor area}

\author{
Goran A. Bogdanovic, Bojana D. Ostojic, and Sladjana B. Novakovic
}

Cryst. Growth Des., Just Accepted Manuscript • DOI: 10.1021/acs.cgd.7b00914 • Publication Date (Web): 02 Feb 2018

Downloaded from http://pubs.acs.org on February 6, 2018

\section{Just Accepted}

"Just Accepted" manuscripts have been peer-reviewed and accepted for publication. They are posted online prior to technical editing, formatting for publication and author proofing. The American Chemical Society provides "Just Accepted" as a service to the research community to expedite the dissemination of scientific material as soon as possible after acceptance. "Just Accepted" manuscripts appear in full in PDF format accompanied by an HTML abstract. "Just Accepted" manuscripts have been fully peer reviewed, but should not be considered the official version of record. They are citable by the Digital Object Identifier (DOI®). "Just Accepted" is an optional service offered to authors. Therefore, the "Just Accepted" Web site may not include all articles that will be published in the journal. After a manuscript is technically edited and formatted, it will be removed from the "Just Accepted" Web site and published as an ASAP article. Note that technical editing may introduce minor changes to the manuscript text and/or graphics which could affect content, and all legal disclaimers and ethical guidelines that apply to the journal pertain. ACS cannot be held responsible for errors or consequences arising from the use of information contained in these "Just Accepted" manuscripts. 


\title{
Short intramolecular O...O contact in some $o$-dialkoxybenzene derivatives generates efficient hydrogen bonding acceptor area
}

\author{
Goran A. Bogdanović* ${ }^{1}$, Bojana D. Ostojić*2 ${ }^{2}$ Sladjana B. Novaković*1 \\ ${ }^{1}$ VINČA Institute of Nuclear Sciences, University of Belgrade, PO Box 522, 11001 Belgrade, Serbia; \\ ${ }^{2}$ Center of Excellence for Environmental Chemistry and Engineering, Institute for Chemistry, Technology and \\ Metallurgy, University of Belgrade, Njegoševa 12, Belgrade 11158, Serbia
}

\begin{abstract}
Statistical analysis of data extracted from the Cambridge Structural Database (CSD) has been used to investigate the crystal structure properties of $o$-dialkoxybenzene derivatives, compounds containing two ether oxygen acceptors in ortho positions of benzene ring. It has been shown that in more than the $90 \%$ of cases the fragment has predictable geometrical characteristics where the two ether oxygens form short interatomic O...O contact (2.57 $\AA$ in average), while Osubstitutents take trans positions, both approximately coplanar with the benzene ring. Such arrangement of oxygen acceptors produces a large and uniform area of the negative electrostatic potential suitable for multiple hydrogen bonding. The acceptor abilities of the O... O system have been investigated by the statistical CSD analysis. The ab initio estimation of the interaction energy in the dimer of $o$-dimethoxybenzene (DMB) and $\mathrm{H}_{2} \mathrm{O}$, employed as a model system, is achieved via high-level electron correlation $\operatorname{CCSD}(\mathrm{T})$ calculation with the CBS extrapolation. The interaction energy is estimated to be $-6.5 \mathrm{kcal} / \mathrm{mol}$. The results indicate the existence of a very flat potential energy surface in the region between methoxy oxygens and that DMB-water is a highly flexible system. The structural role of the $\mathrm{O} \ldots \mathrm{O}$ acceptor system is particularly interesting considering its ability to form multiple hydrogen bonding.

*Goran A. Bogdanović (goranb@vin.bg.ac.rs)

VINČA Institute of Nuclear Sciences, University of Belgrade, PO Box 522, 11001 Belgrade, Serbia. Phone: +381 113408766

Fax: +381118065829

*Bojana D. Ostojić (bojana.ostojic@gmail.com)

Center of Excellence for Environmental Chemistry and Engineering, Institute for Chemistry, Technology and Metallurgy, University of Belgrade, Njegoševa 12, Belgrade 11158, Serbia

Phone: +381 113640230

*Sladjana B. Novaković (snovak@vin.bg.ac.rs)

VINČA Institute of Nuclear Sciences, University of Belgrade, PO Box 522, 11001 Belgrade, Serbia.

Phone: +381113408766

Fax: +381118065829
\end{abstract}




\title{
Short intramolecular O... contact in some $o$ -
}

\section{dialkoxybenzene derivatives generates efficient}

\section{hydrogen bonding acceptor area}

\author{
Goran A. Bogdanovic $*^{1}$, Bojana D. Ostojić* ${ }^{2}$, Sladjana B. Novaković* ${ }^{1}$ \\ ${ }^{1}$ VINČA Institute of Nuclear Sciences, University of Belgrade, PO Box 522, 11001 Belgrade, \\ Serbia; \\ ${ }^{2}$ Center of Excellence for Environmental Chemistry and Engineering, Institute for Chemistry, \\ Technology and Metallurgy, University of Belgrade, Njegoševa 12, Belgrade 11158, Serbia
}

\begin{abstract}
Statistical analysis of data extracted from the Cambridge Structural Database (CSD) has been used to investigate the crystal structure properties of $o$-dialkoxybenzene derivatives, compounds containing two ether oxygen acceptors in ortho positions of benzene ring. It has been shown that in more than the $90 \%$ of cases the fragment has predictable geometrical characteristics where the two ether oxygens form short interatomic O... $\mathrm{O}$ contact $(2.57 \AA$ in average), while Osubstitutents take trans positions, both approximately coplanar with the benzene ring. Such
\end{abstract}


arrangement of oxygen acceptors produces a large and uniform area of the negative electrostatic potential suitable for multiple hydrogen bonding. The acceptor abilities of the O...O system have been investigated by the statistical CSD analysis. The ab initio estimation of the interaction energy in the dimer of $o$-dimethoxybenzene (DMB) and $\mathrm{H}_{2} \mathrm{O}$, employed as a model system, is achieved via high-level electron correlation $\operatorname{CCSD}(\mathrm{T})$ calculation with the CBS extrapolation. The interaction energy is estimated to be $-6.5 \mathrm{kcal} / \mathrm{mol}$. The results indicate the existence of a very flat potential energy surface in the region between methoxy oxygens and that DMB-water is a highly flexible system. The structural role of the $\mathrm{O} \ldots \mathrm{O}$ acceptor system is particularly interesting considering its ability to form multiple hydrogen bonding.

\section{Introduction}

Hydrogen bonds have an essential influence on structure, stability and function of a diverse range of chemical and biological systems. Recognition of their importance prompted the investigation on different types of intermolecular contacts which can guide and stabilize the supramolecular organization in crystal. ${ }^{1-4}$ Among the different methods employed in investigation of noncovalent interactions, the statistical analysis of crystal structure data retrieved from the Cambridge Structural Database (CSD) ${ }^{5}$ has proven as a very powerful and informative tool. Based on a large subset of structures comprising the same structural fragment, the CSD analyses can provide a reliable insight into the structural properties of an entire molecular class. This general information on structural behavior of the potential building blocks can be further very useful for rapidly developing research fields such as crystal engineering and solid state structure prediction. ${ }^{3,6-9}$ It is of special interest for supramolecular studies to understand and predict the preferred contacts of those structural fragments, which frequently appear as 
components of the important natural and synthetic products. The fragment presented in Figure 1 is common for a number of compounds with interesting structural features, ${ }^{10-15}$ different natural products with biological activity (papaverine, dopamine, veratrole, glaucine, vanillin) ${ }^{16,17}$, a number of synthetic drugs ${ }^{18-20}$, as well as of host materials based on crown ethers. ${ }^{21-23}$

Regardless the general abundance of the $o$-dialkoxybenzene fragment, to our knowledge, no systematic study of its solid state structural properties or the potential role in supramolecular arrangement has been performed. From that reason and taking into account that the CSD stores a great number of structures containing this fragment, we carried out a statistical analysis in attempt to explore the structural preferences of the fragment and the hydrogen bonding ability of its $\mathrm{O} \ldots \mathrm{O}$ ether acceptor pair. The ether oxygens are generally known as weak bases and therefore very poor acceptors of hydrogen bonds. ${ }^{24-27}$ However, in aromatic ethers containing two mutually ortho positioned ether oxygens (Figure 1), the proximity of O-acceptors generates a wide electron-rich area which can be efficient as hydrogen bonding acceptor site. In our analysis of structural data extracted from CSD we devoted special attention to this subject, aiming to evaluate the cooperativity of weak ether acceptors and efficiency of O...O system as a whole.

Simple aromatic ethers like $o$-dimethoxybenzene (DMB) and methoxybenzene (anisole) are often investigated by experimental and computational methods since they are found challenging in view of conformational properties and preferable interaction sites. ${ }^{28-40}$ A hydrogen bonded complex of DMB and water molecule has been studied experimentally employing the rotationally resolved fluorescence excitation spectroscopy technique. ${ }^{28}$ The theoretical investigation of the DMB- $\mathrm{H}_{2} \mathrm{O}$ dimer has not been published thus far and here we present our results on this dimer used as a model system for hydrogen bond acceptor properties of the DMB molecule. An accurate determination of binding energy in an optimized $\mathrm{DMB}-\mathrm{H}_{2} \mathrm{O}$ complex is 
performed via high-level electron correlation $\operatorname{CCSD}(\mathrm{T})$ calculation. ${ }^{41}$ For complete insight into acceptor ability of a joined O...O ether pair (Figure 1) we also employed the electrostatic potential anaysis ${ }^{42}$ and the topological analyses of total electron density (Bader's quantum theory of atom in molecules) ${ }^{43}$ in order to examine the quantitative electrostatic features of the formed intermolecular contacts at a subatomic level.

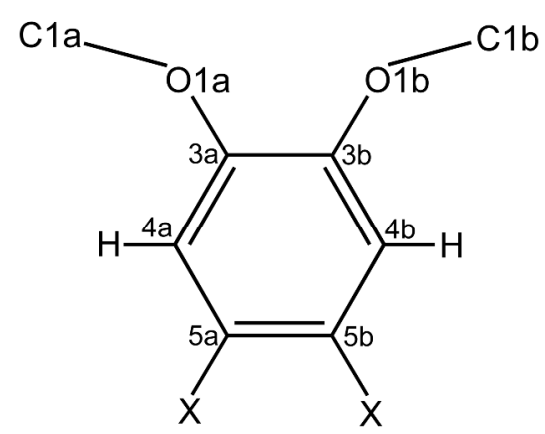

Figure 1. Fragment used in the CSD search $(\mathrm{X}=$ any non-metal atom).

\section{Methodology}

Cambridge Structural Database ${ }^{5}$ has been searched for crystal structures containing the fragment presented in Figure 1. In order to identify the preferential orientation of the oxygen substituents, only acyclic structures were considered in this analysis. Also, to avoid the potential influence of the metal ion which could favor the coplanarity of the O...O pair by coordination to oxygen atoms, the crystal structures of organometallic compounds were excluded from the main survey. The initial CSD search identified 2572 organic, C1-acyclic crystal structures comprising the structural fragment presented in Figure 1. In the subsequent search, the following restrictions were added to increase the crystallographic quality of extracted data and the reliability of statistical analysis: $R$-factor $\leq 7.5 \%$; three-dimensional coordinates for all atoms determined; no disorder or errors; polymeric structures excluded; no ions, no powder structures. The statistical 
study on structural properties of compounds containing the fragment in Figure 1 finally included 1500 crystal structures (CSD refcodes of the structures are listed in Supporting information). For examination of the ability of the O...O system for hydrogen bonding, the hydrogen atoms positions in 1500 extracted structures were normalized to the neutron diffraction values. Analysis of the hydrogen bonding abilities was based on two subsets satisfying the following criteria: a) $\mathrm{O} . . . \mathrm{H} \leq 3.0 \AA$ and $\mathrm{D}-\mathrm{H} . . . \mathrm{O} \geq 110^{\circ}$ and $\left.\mathrm{b}\right) \mathrm{O} . . . \mathrm{H} \leq 2.6 \AA$ and $\mathrm{D}-\mathrm{H} . . . \mathrm{O} \geq 110^{\circ}$. The plots showing the experimental distribution of the hydrogen bonding donors around the O...O system were created using the IsoGen and IsoStar. ${ }^{44}$

\section{Computational details}

Electrostatic potential (EP) of the selected crystal structures was calculated at the B3LYP/6$311++\mathrm{G}(2 \mathrm{~d}, 2 \mathrm{p})$ level of theory using Gaussian09. ${ }^{45}$ The Kohn-Sham orbitals calculated at the same level of theory were used for the topological analysis by AIM2000. ${ }^{46}$ The theoretical electron density for the optimized geometry of DMB molecule was obtained by the multipole refinement performed in $\mathrm{XD}^{47}$ on the basis of theoretical structure factors calculated by DENPROP. $^{48}$

Taking into account that DMB is characterized by several functional groups such as aromatic ring, H-bond donor, H-bond acceptor and the methyl group, it can be involved in different intermolecular interactions. Therefore, $\mathrm{DMB}-\mathrm{H}_{2} \mathrm{O}$ is particularly interesting from the theoretical point of view. The geometry optimizations of $\mathrm{DMB}$ and $\mathrm{DMB}-\mathrm{H}_{2} \mathrm{O}$ were performed in the framework of the $\mathrm{C} 1$ point group. The frequency calculations showed no imaginary values for the minima of the obtained structures while for the optimized stationary points showed one imaginary value. In order to investigate the potential energy surface (PES) between methoxy 
oxygens we performed a scan of PES in the ground electronic state of $\mathrm{DMB}-\mathrm{H}_{2} \mathrm{O}$ along the selected coordinate. The PES was scanned so that in-plane bending angle $\mathrm{O}-\mathrm{O} 1 \mathrm{a}-\mathrm{C} 3 \mathrm{a}$ (or $\mathrm{O}-$ $\mathrm{O} 1 \mathrm{~b}-\mathrm{C} 3 \mathrm{~b}$ ) was kept fixed at the selected angles from the range $152^{\circ}-130^{\circ}$ around the equilibrium value $\left(137^{\circ}\right)$ whereas a full relaxation of molecular geometry of the dimer was allowed. The in-plane bending angle was varied with the increment of $2^{\circ}$. The zero-point vibrational energies (ZPVE) have been evaluated by means of harmonic vibrational frequencies. We have also performed the investigation of interaction energy between DMB and several donor molecules in the model systems based on the observed intermolecular contacts obtained from the CSD.

In order to account for the basis set superposition error (BSSE) for the estimation of the interaction energies we employed the counterpoise-correction method. ${ }^{49}$ The interaction energy can be calculated as the difference between the energy of the dimer $\left(\mathrm{E}_{\mathrm{AB}}{ }^{\mathrm{AB}}(\mathrm{AB})\right)$ and the sum of the monomer energies calculated in the dimer basis set $\left(E_{\mathrm{A}}{ }^{\mathrm{AB}}(\mathrm{AB}), E_{\mathrm{B}}{ }^{\mathrm{AB}}(\mathrm{AB})\right)$ :

$$
\Delta E_{\text {int }}{ }^{\mathrm{CP}}=E_{\mathrm{AB}}{ }^{\mathrm{AB}}(\mathrm{AB})-\left(E_{\mathrm{A}}{ }^{\mathrm{AB}}(\mathrm{AB})+E_{\mathrm{B}}{ }^{\mathrm{AB}}(\mathrm{AB})\right)
$$

The subscripts $\mathrm{AB}, \mathrm{A}$, and $\mathrm{B}$ denote the molecular system, the dimer $\mathrm{DMB}-\mathrm{H}_{2} \mathrm{O}, \mathrm{DMB}$ and $\mathrm{H}_{2} \mathrm{O}$ monomers, respectively. The superscripts $\mathrm{AB}$ denote the basis set of the dimer DMB- $\mathrm{H}_{2} \mathrm{O}$ while the $(\mathrm{AB})$ in brackets denotes that the calculations are performed at the geometry of the dimer DMB- $\mathrm{H}_{2} \mathrm{O}$. In our calculations we have also accounted for the deformation of monomers upon complexation in the $\mathrm{DMB}-\mathrm{H}_{2} \mathrm{O}$ dimer. If the deformation energies are included in the $\mathrm{CP}$ corrected interaction energy, one obtains the binding energy:

$$
\Delta E_{\text {bind }}{ }^{\mathrm{CP}}=E_{\mathrm{AB}}{ }^{\mathrm{AB}}(\mathrm{AB})-E_{\mathrm{A}}{ }^{\mathrm{A}}(\mathrm{A})-E_{\mathrm{B}}{ }^{\mathrm{B}}(\mathrm{B})-E_{\mathrm{A}}{ }^{\mathrm{AB}}(\mathrm{AB})+E_{\mathrm{A}}{ }^{\mathrm{A}}(\mathrm{AB})-E_{\mathrm{B}}{ }^{\mathrm{AB}}(\mathrm{AB})+E_{\mathrm{B}}{ }^{\mathrm{B}}(\mathrm{AB})
$$

where (A) and (B) denote the optimized geometries of the isolated monomers. The correlation contributions to the interaction energy are obtained from the expression (2) involving the 
corresponding correlation energies calculated using the second-order Møller-Plesset perturbation theory $(\mathrm{MP} 2)^{50}$ and coupled-cluster singles and doubles augmented by a perturbational correction for connected triple excitations $(\operatorname{CCSD}(\mathrm{T}))[\operatorname{CCSD}(\mathrm{T})]^{41}$ The geometry optimizations and MP2 energy calculations have been performed with the Gaussian program packages ${ }^{45,51}$ whereas for the CCSD(T) calculations we employed Molpro suite of programs. ${ }^{52}$

Two-point extrapolation scheme $e^{53,54}$ is employed in order to obtain the complete basis set (CBS) extrapolated value of the interaction energy at the MP2 level of theory

$$
\Delta E_{\mathrm{MP} 2, \mathrm{X}}=\Delta E_{\mathrm{MP} 2, \mathrm{CBS}}+\mathrm{A} \mathrm{X}^{-3}
$$

where $\Delta E_{\mathrm{MP} 2, \mathrm{X}}$ is the MP2 energy obtained using the basis set with the cardinal number $\mathrm{X}$ and $\triangle \mathrm{E}_{\mathrm{MP2}, \mathrm{CBS}}$ is the basis set limit value of the MP2 correlation energy. Two separate energy calculations are performed using the smaller (aug-cc-pVDZ) and the larger basis set (aug-ccpVTZ). The CBS correlation energies at the $\operatorname{CCSD}(\mathrm{T})$ level of theory are obtained using

$$
\Delta E_{\mathrm{CCSD}(\mathrm{T}), \mathrm{CBS}}=\Delta E_{\mathrm{MP} 2, \mathrm{CBS}}+\left(\Delta E_{\mathrm{CCSD}(\mathrm{T}), \text { aug-cc-pVDZ}}-\Delta E_{\mathrm{MP} 2, \text { aug-cc-pVDZ }}\right)
$$

The intermolecular interaction between DMB and $\mathrm{H}_{2} \mathrm{O}$ was analyzed by means of the energy decomposition analysis (EDA) developed by Ziegler and Rauk ${ }^{55}$ following the procedure suggested by Morokuma ${ }^{56}$ as well as with the Extended Transition State (ETS) scheme with the Natural Orbitals for Chemical Valence (NOCV) method (ETS-NOCV) ${ }^{57-59}$. In the EDA and ETS-NOCV calculations the Becke-Perdew exchange-correlation functional (BP86) ${ }^{60,61}$ with the inclusion of the dispersion correction (BP86-D) ${ }^{62}$ was applied. A standard triple-zeta STO basis containing two sets of polarization functions was adopted for elements (TZ2P). The bonding analysis has been carried out with the program package ADF. ${ }^{63-65}$ The contours of the deformation densities were plotted using the ADF-GUI interface. 


\section{Results and Discussion}

\section{Preferential structural properties of $o$-dialkoxybenzene fragment in solid state}

The CSD search resulted in total of 2572 crystal structures containing the structural motif shown in Figure 1, however for a more refined statistical analysis, we selected a subset of 1500 high quality structures, relaying purely on crystallographic criteria (see Methodology section). As expected, within 1500 selected crystal structures the two ether oxygen atoms are practically coplanar with the benzene ring, thus in majority of cases the torsion angle $\mathrm{O} 1 \mathrm{a}-\mathrm{C} 3 \mathrm{a}-\mathrm{C} 3 \mathrm{~b}-\mathrm{O} 1 \mathrm{~b}$ has the value of $\pm 3^{\circ}$ (Figure $\mathrm{S} 1$ in Supporting information). Histogram with the O1a...O1b contacts given in Figure 2a indicates a very short distance between these two atoms which is mainly in the range from 2.54 to $2.61 \AA{ }^{66}$ This short intramolecular separation surprises because in more than $90 \%$ of the structures the two O1-C1 bonds (Figure 1) also lie in plane of the benzene ring, while having the trans mutual orientation. Figure $2 \mathrm{~b}$ shows the distribution of the torsion angles $\mathrm{C} 1 \mathrm{a}-\mathrm{O} 1 \mathrm{a}-\mathrm{C} 3 \mathrm{a}-\mathrm{C} 3 \mathrm{~b}(\mathrm{~T} 1)$ and $\mathrm{C} 1 \mathrm{~b}-\mathrm{O} 1 \mathrm{~b}-\mathrm{C} 3 \mathrm{~b}-\mathrm{C} 3 \mathrm{a}(\mathrm{T} 2)$ and indicates a much higher frequency of the structures heaving both $\mathrm{O} 1-\mathrm{C} 1$ bonds coplanar with the phenyl ring (region I marked in red), in comparison to those with the non-coplanar positions of one or both O1-C1 bonds (region II and III marked in green and blue, respectively). This practically means that the free electron pairs of the oxygen atoms confront each other regardless of possibility of escaping the repulsion by rotation about the formally single $\mathrm{C} 3-\mathrm{O} 1$ bonds (Figure 1). Regions II and III in Figure 2b confirm the existence of structures with the non-coplanar $\mathrm{O} 1-\mathrm{C} 1$ bonds (refcodes of structures containing non-coplanar fragments are listed in SI), however the region II indicates a small number of structures with one $\mathrm{O} 1-\mathrm{C} 1$ bond non-coplanar with the phenyl ring, while practically negligible number of structures with both $\mathrm{O} 1-\mathrm{C} 1$ bonds out of the ring belongs 
to the region III. These statistical findings indicate a highly predictable conformation of the $o$ dialkoxybenzene fragment regardless the structural diversity of the compounds.

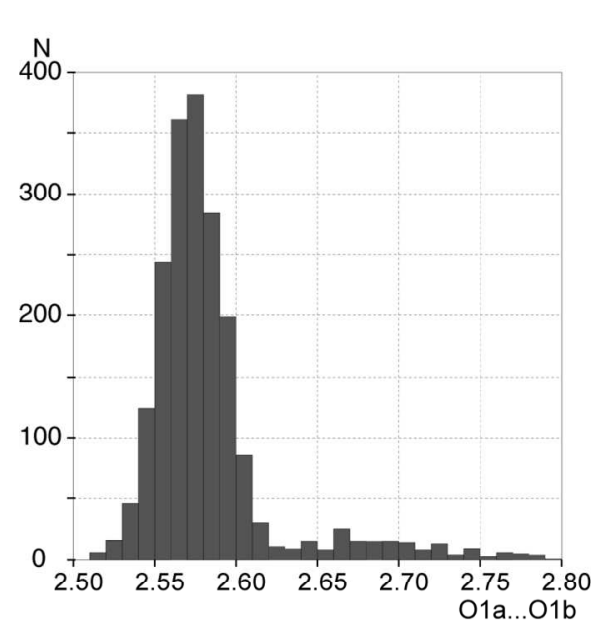

(a)

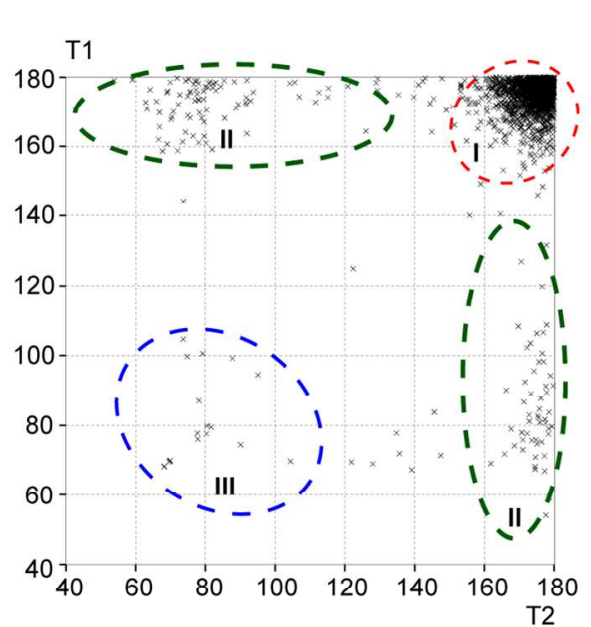

(b)

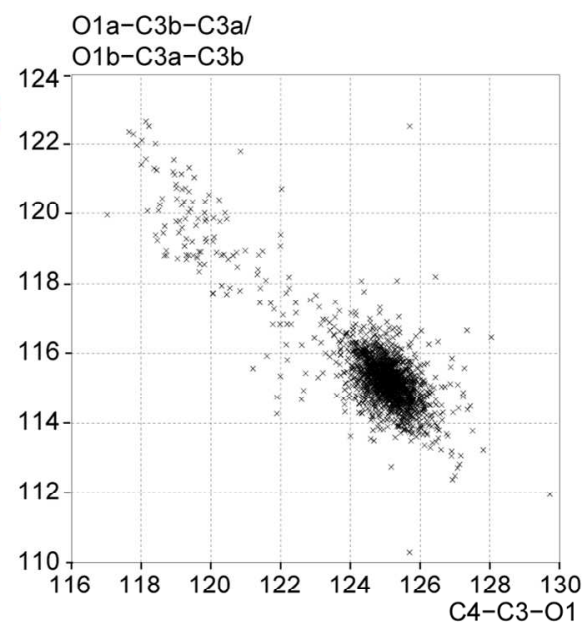

(c)

Figure 2. (a) distribution of $\mathrm{O} \ldots \mathrm{O}$ distances $(\AA)$; (b) torsion angles $\mathrm{T} 1=\mathrm{C} 1 \mathrm{a}-\mathrm{O} 1 \mathrm{a}-\mathrm{C} 3 \mathrm{a}-\mathrm{C} 3 \mathrm{~b} v s$. $\mathrm{T} 2=\mathrm{C} 1 \mathrm{~b}-\mathrm{O} 1 \mathrm{~b}-\mathrm{C} 3 \mathrm{~b}-\mathrm{C} 3 \mathrm{a}\left(^{\circ}\right)$. Red (I) both $\mathrm{O} 1-\mathrm{C} 1$ in the benzene plane (see also Figure S2), green (II) one $\mathrm{O} 1-\mathrm{C} 1$ out of plane, blue (III) both $\mathrm{O} 1-\mathrm{C} 1$ out of plane; (c) $\mathrm{O} 1-\mathrm{C} 3-\mathrm{C} 3$ (in both fragments) vs. $\mathrm{C} 4-\mathrm{C} 3-\mathrm{O} 1$ angles $\left(^{\circ}\right)$.

It should be noted that the observed existence of the structures with one $\mathrm{O} 1-\mathrm{C} 1$ bond nearly perpendicular to the phenyl ring while another $\mathrm{O} 1-\mathrm{C} 1$ bond is mostly coplanar with the phenyl ring, can be understood if one takes into account the stable conformations of DMB. DMB possesses the most stable conformation (conformer A) in which two methoxy groups are both coplanar with the benzene ring and also another one, the stable conformation in which one methoxy group is nearly perpendicular to the benzene ring and another methoxy group is coplanar with the ring (conformer B) which is only $0.16 \mathrm{kcal} / \mathrm{mol}$ less stable than the conformer A. ${ }^{40}$ The comparative analysis of the torsional potentials of DMB and anisole shows that perpendicular position in anisole is energetically much higher $(2.4 \mathrm{kcal} / \mathrm{mol})$ compared to the 
planar conformation which indicates that second methoxy group in ortho position stabilizes the perpendicular conformation in DMB. This fact is reflected in existence of two preferential positions, coplanar and perpendicular, for building intermolecular interactions.

Considering that a free molecule can partly influence its O...O distance through an in-plane motion of the ether oxygen atoms, we have also examined the deformation of angles $\mathrm{C} 4-\mathrm{C} 3-\mathrm{O} 1$ and $\mathrm{O} 1 \mathrm{a}-\mathrm{C} 3 \mathrm{a}-\mathrm{C} 3 \mathrm{~b}$ (i.e. $\mathrm{O} 1 \mathrm{~b}-\mathrm{C} 3 \mathrm{~b}-\mathrm{C} 3 \mathrm{a}$ ) from the expected value of $120^{\circ}$ (Figure $2 \mathrm{c}$ ). The plot clearly shows that in the vast majority of structures $\mathrm{C} 4-\mathrm{C} 3-\mathrm{O} 1$ and $\mathrm{O} 1-\mathrm{C} 3-\mathrm{C} 3$ angles have the approximate values of $125^{\circ}$ and $115^{\circ}$, respectively (Figure S5 illustrates the distribution of two angles in more details). Such an angular distortion practically means further shortening of the O...O distance and the tendency of the ether oxygens to mutually approach, orienting the free electron pairs toward each other.

To examine the actual charge density distribution within the structural fragment given in Figure 1 we performed a multipole modeling (based on Hansen-Coppens formalism ${ }^{67}$ ) of the electron density in the optimized DMB molecule. Deformation density maps in Figure 3a show the distribution of electron density in the region between the oxygen atoms in two orthogonal planes. Indeed, the maxima of electron density belonging to free electron pairs are clearly aligned and directed to each other, positioned at a closer distance than the oxygen nuclei $(2.48$ and $2.59 \AA$, respectively). Histogram in Figure S6 shows the distribution of dihedral angles between the two planes containing $\mathrm{C} 3 / \mathrm{O} 1 / \mathrm{C} 1$ atoms which mirror the mutual position of the electron pairs belonging to the neighboring $\mathrm{O}$ atoms in the real cases extracted from CSD. In vast majority of structures this dihedral angle remains below $10^{\circ}$ indicating the alignment of the neighboring electron pairs. We can therefore conclude that the $o$-dialkoxybenzene fragment (Figure 1), although belonging to molecules of different composition and size, shows very 
predictable structural behavior in which: (a) the neighboring $\mathrm{C} 1-\mathrm{O} 1$ bonds (Figure 1) both lie in the plane of the phenyl ring and (b) oxygen atoms face each other at a short distance with free electron pairs pointing to the space in-between (Figure 3a).



(a)



(b)



(c)

Figure 3. (a) Deformation electron density distribution in two planes of DMB system: plane of the phenyl ring (above); plane passing through the maxima of electron pairs of the $\mathrm{O}$ acceptors (dashed green, below). Equivalent Laplacian distribution is given in Figure S7. Spatial distribution of EP isosurfaces at $+0.1 /-0.05$ au (grey/red, respectively) in (b) DMB and (c) anisole.

A system with such a closely positioned two ether $\mathrm{O}$ atoms could be very interesting as the potential hydrogen bonding acceptor area. Namely, this arrangement of the oxygen atoms electron density pairs gives rise to a wide region of the negative electrostatic potential (EP) which is symmetrically distributed around the diether fragment (Figure 3b). EP is generally known as an excellent descriptor of the hydrogen bonding ability and of the acceptor strength in different chemical environments. ${ }^{41,68,69}$ In the case of DMB the closeness of oxygen electron densities generates a fused area of the negative EP (Figure $3 \mathrm{~b}$ ) with the minimum value of $V_{\min }$ 
-0.0727 au. This value is noticeable increased in magnitude in comparison to $V_{\min }-0.0539$ au of monoether anisole (Figure 3c). More importantly, a direct comparison of EP isosurfaces of DMB and anisole at the equal magnitude e.g. -0.045 au (see also Figure S8) indicates nine times larger volume of space encompassed by the isosurface of the former. The ratio between the volumes further increases for the more negative EP values, Figure 3b,c. This comparison indicates significantly improved acceptor abilities of DMB in comparison to anisole, which results from the cooperativity of the two oxygen acceptors. Significance of the cooperativity between O atoms is also evident from the DMB comparison with 1,3- and 1,4-DMB analogues, where EP generated by two separated oxygens closely resemble those from anisole, in magnitude $\left(V_{\min }\right.$ -0.0547 and -0.0572 au, respectively) as well as in spatial distribution (Figure S9). Finally, it is important to notice that for the majority of structures extracted from CSD the EP generated by O...O system keeps consistent shape and magnitude (Figure S10) which permits to anticipate its behavior in the various supramolecular structures. Similar EP features can be observed even for structures with the voluminous alkoxy substituents (Figure S10, refcodes: DAYVAB, DAYSUS, EGOVIF, IDOQAU, URAWVEQ, WOQMIZ).

It is interesting to investigate the effect of the C3-alkoxy substituent (Figure 1) on the geometry of binding site. Namely, in great majority of crystal structures extracted from CSD (1210 from 1500) the compounds contain pairs of methoxy substituents i.e. both $\mathrm{C} 1$ atoms (Figure 1) belong to the methyl group, while there are 1396 structures where at least one $\mathrm{C} 1$ atom is a methyl. The number of structures where $\mathrm{C} 1$ belongs to a group larger than methyl is significantly smaller (283 structures with $\mathrm{C} 1-\mathrm{Z}$ group, where the atom attached to $\mathrm{C} 1$ is non- $\mathrm{H}$ atom; 78 structures with phenyl group). The examination of these structures shows that the change of the C3-alkoxy substituents has little influence on the O1a...O1b distance, as well as on 
the distribution of corresponding $\mathrm{O} 1-\mathrm{C} 3-\mathrm{C} 3$ and $\mathrm{C} 4-\mathrm{C} 3-\mathrm{O} 1$ angles and that the values of these parameters closely agree with the findings from the main analysis. On the other hand, the effect on substituents on the torsion angles $\mathrm{C} 1 \mathrm{a}-\mathrm{O} 1 \mathrm{a}-\mathrm{C} 3 \mathrm{a}-\mathrm{C} 3 \mathrm{~b}$ and $\mathrm{C} 1 \mathrm{~b}-\mathrm{O} 1 \mathrm{~b}-\mathrm{C} 3 \mathrm{~b}-\mathrm{C} 3 \mathrm{a}$ seems more pronounced as considerable portion of these structures has one or both $\mathrm{O} 1-\mathrm{C} 1$ fragments nonplanar with the phenyl ring. This is mostly the case when the both alkoxy substituents are voluminous groups producing the steric hindrance or the subtituents contain strong hydrogen bonding sites involved in additional interactions.

\section{CSD analysis of the acceptor ability of O...O system}

The CSD analysis has been further employed to examine the real acceptor ability and capacity of the O...O systems from $o$-dialkoxybenzene fragment (Figure 1) to form hydrogen bonding. In the subsequent CSD search the intermolecular interaction between the ether acceptor system and the hydrogen donor was assumed if it satisfied the criteria $\mathrm{O} \ldots \mathrm{H} \leq 3.0 \AA$ and $\mathrm{D}-\mathrm{H} \ldots \mathrm{O} \geq 110^{\circ}$ with at least one of the oxygen acceptors. Almost all crystal structures i.e. 1477 from 1500 extracted structures $(98.5 \%)$ satisfied the given criteria by forming 7240 intermolecular O...H contacts. This result corresponds to the average number of 4.9 contacts per structure, however an inspection of individual cases revealed that up to $8 \mathrm{D}-\mathrm{H}$... $\mathrm{O}$ interactions can simultaneously be formed with the particular O...O system (Figure 4; for additional examples see Figure S11). This multiple hydrogen bonding can be explained by the existence of a large region of the negative EP (Figure 3b) which allows the simultaneous accommodation of several H-donor groups. A reduction of the acceptor...donor distance to $\mathrm{O} . . . \mathrm{H} \leq 2.6 \AA$, resulted in $1195(79.7 \%)$ structures with 2449 contacts. Interestingly, an equivalent analysis of the anisole oxygen acceptor abilities, showed a considerable lower portion i.e. $48.8 \%$ of structures forming the $\mathrm{D}-\mathrm{H}$...O interactions 
within the same geometrical limits (4875 of 9981 structures containing the anisole fragment, Figure S3b, formed 6512 contacts with $\mathrm{O} . . . \mathrm{H} \leq 2.6 \AA$ ).



Figure 4 Examples of multiple hydrogen bonding interactions with $\mathrm{O} . . . \mathrm{O}$ system $(\mathrm{O} \ldots \mathrm{H} \leq 3.0 \AA$ and $\mathrm{D}-\mathrm{H} \ldots \mathrm{O} \geq 110^{\circ}$ ). Additional examples can be found in Figure S11.

Histograms in Figure 5 show the spatial distribution of the interacting $\mathrm{H}$ atoms with regard to the O...O system defined by the P1 plane which contains these two acceptors. Thus, the short H...P1 distance indicates that the $\mathrm{H}$ atom lies in the plane or close to the plane of the acceptors. For two subsets of structures, i.e. with the O...H distances restricted to 2.6 (light gray) and with the O...H distances up to $3.0 \AA$ (the whole dataset given in dark grey), the histograms show that the interactions can take place in the level of oxygen acceptors as well as out of this plane, following the distribution of EP. Subset of structures with O...H distances restricted to $2.6 \AA$ shows only a slight preference of the $\mathrm{H}$ atoms to accumulate in the level of P1 plane and hence to approach closer to the EP minimum located between the oxygen atoms. The longer contacts, on the other hand, show a clear tendency to accumulate out of the P1 plane (at $2.4-2.6 \AA$ 
above/below P1, Figure 5) which is in accordance with the symmetrical expansion of the negative EP's surface area above and below the O...O system at longer distances (Figure 3b, Figure 6).

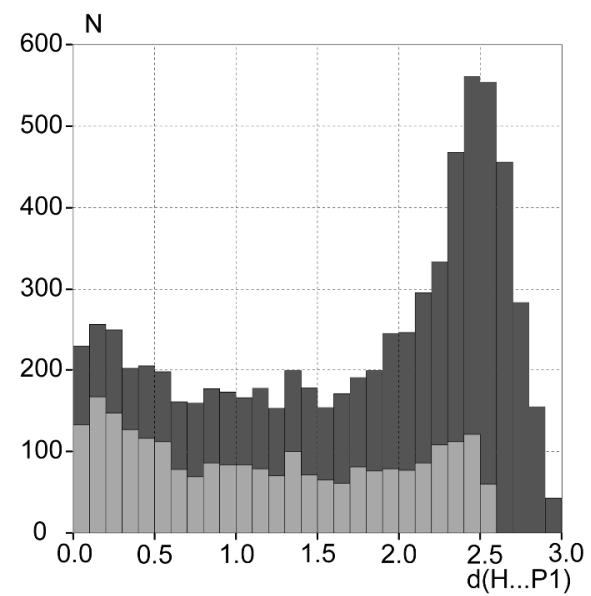

Figure 5. Distribution of $\mathrm{O} \ldots \mathrm{H}$ contacts with respect to the $\mathrm{O} \ldots \mathrm{O}$ acceptor system for the subsets with distances $\mathrm{O} \ldots \mathrm{H} \leq 3.0 \AA$ (dark gray) and $\mathrm{O} \ldots \mathrm{H} \leq 2.6 \AA$ (light gray). The parameter $\mathrm{d}(\mathrm{H} . . . \mathrm{P} 1)$ represents the distance of interacting $\mathrm{H}$ atom from the plane (P1) containing oxygen acceptors and atoms of phenyl ring.

The spatial distribution of the extracted intermolecular contacts generated by Isogen, along with the distribution of the negative EP surface in Figure 6 indeed shows the agreement between the radial expansion of EP and the expansion of the donor groups above/below the P1 plane (Figure 5). The shortest hydrogen bonds (O...H distances up to $2.3 \AA$ given in Figure $6 \mathrm{~b})$ display similar radial distribution with no particular preference regarding the spatial position of the donor groups. This may indicate a similar influence of the O...O acceptor system within a wide area surrounding the system, and its accessibility from different directions. In addition, the 
shortest interactions manly involve the polar hydrogen bonding donor groups, $\mathrm{O}-\mathrm{H}$ and $\mathrm{N}-\mathrm{H}$ (Figure 6b), while the number of weak $\mathrm{C}-\mathrm{H}$ donors increases at longer distances (Figure 6a).

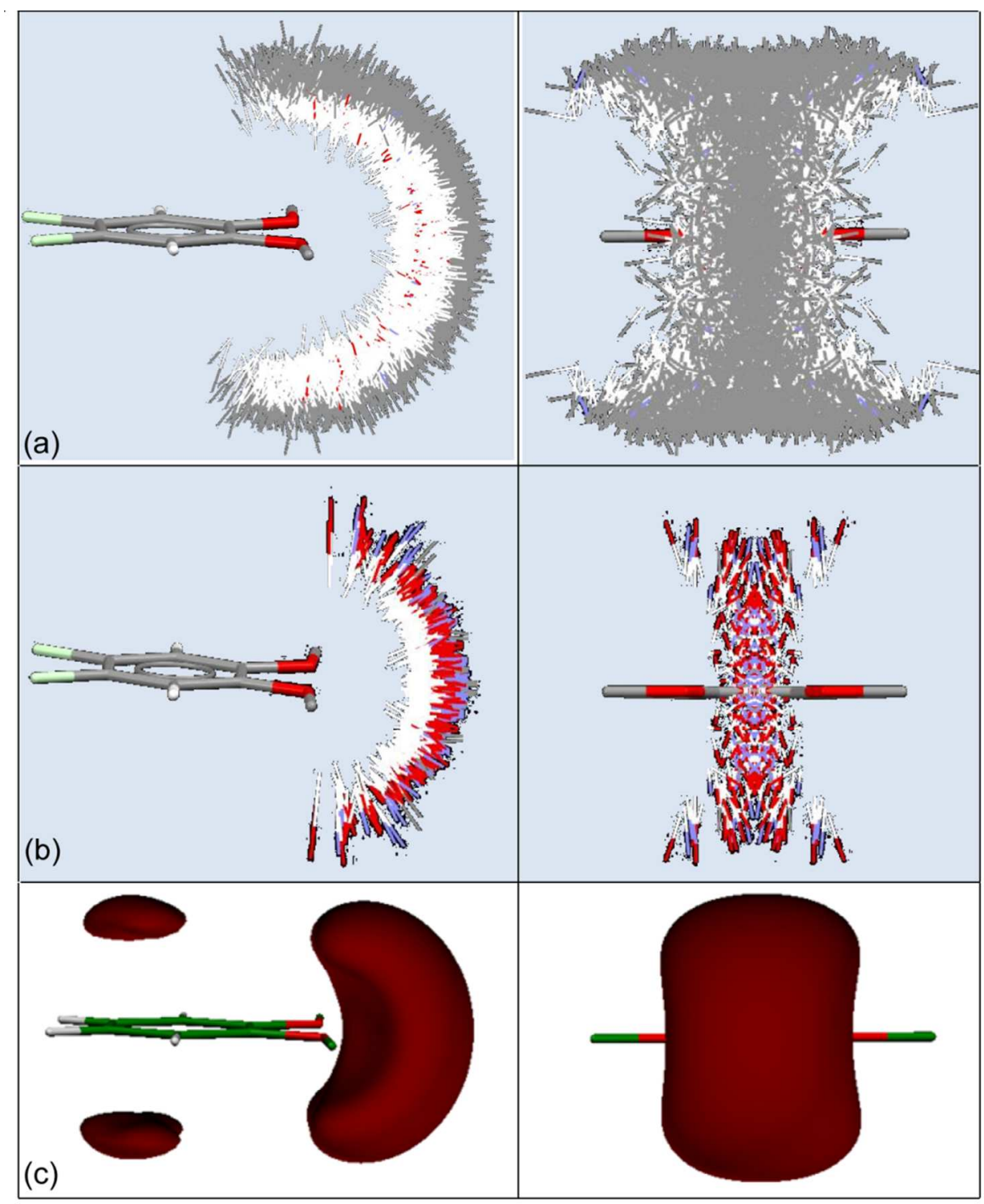

Figure 6. CSD-based spatial distribution of $\mathrm{D}-\mathrm{H}$ donor groups around $\mathrm{O} \ldots \mathrm{O}$ system relative to the spatial distribution of EP. In two projections: IsoStar plots for D-H...O interactions with O...H distances up to (a) 3.0 and (b) $2.3 \AA$; (c) EP of DMB at -0.025 au. Figure $\mathrm{S} 12$ shows the distribution of D-H donor groups positioned within $2.6 \AA$ from $\mathrm{O}$ acceptors. 
To investigate in more details the correlation between the shortest hydrogen bonds, the nature of H-donors and their relative position with respect to O... S system, in further CSD analysis we focused on interactions with the most significant hydrogen bonding donors, $\mathrm{O}-\mathrm{H}$ and $\mathrm{N}-\mathrm{H}$. Due to a small number of structures containing the $\mathrm{O}-\mathrm{H}$ or $\mathrm{N}-\mathrm{H}$ donors, a joined analysis of their distribution and tendencies with respect to the acceptor system has been performed.

Among the 1477 crystal structures containing the D-H...O interactions there are only 140 structures with the $\mathrm{O}-\mathrm{H} \ldots \mathrm{O}$ or $\mathrm{N}-\mathrm{H} \ldots \mathrm{O}$ interactions. The corresponding $\mathrm{OH} / \mathrm{NH}$ donors are engaged in 294 interactions in total, while 265 interactions (thus over $90 \%$ ), have the O...H distances $\leq 2.6 \AA$. Histogram in Figure S13 shows the distribution of O...H distances from O$\mathrm{H} . . \mathrm{O}$ and $\mathrm{N}-\mathrm{H} . . . \mathrm{O}$ interactions and points to significantly high number of contacts at short distances. Corresponding $d(\mathrm{H} . . . \mathrm{P} 1)$ histogram (Figure S14) analogue to that in Figure 5, shows that the $\mathrm{H}$ atoms belonging to $\mathrm{O}$ or $\mathrm{N}$ tend to accumulate in the level of $\mathrm{O}$... O plane. However, there are numerous cases when the formed hydrogen bonds engage the $\mathrm{OH} / \mathrm{NH}$ donors placed significantly above/below the O...O plane. This observation is again in agreement with the distribution of EP which shows the minimum values in the plane of the oxygen acceptors and favors the accumulation of polar donors close to this plane.

Regardless the type of the available donor groups the topological analysis confirms that the O...O acceptor system can be involved in multiple hydrogen bonding. Thus for the structures with CSD refcodes: RABWIA, FOTKUW and ITUCEG, ${ }^{70-72}$ forming the 4,5 and 6 D-H...O contacts (with $\mathrm{O} \ldots \mathrm{H} \leq 3 \AA$ ), the topological analysis ${ }^{43}$ identified 4,5 and 6 bond paths and the corresponding bond critical points $(b c p s)$, respectively. The electron density in $b c p s\left(\rho_{\text {bcp }}\right)$ ranges from the values typical for very strong hydrogen bonds $\left(\mathrm{RABWIA}^{70}\right.$ : O-H... O: O...H $=1.866 \AA$, $\rho_{\text {bcp }} 0.201$ e $\AA^{-3}$ and Laplacian, $\nabla^{2} \rho_{\text {bcp }} 2.17$ e $\AA^{-5}$ ) to those revealing rather weak interactions 
$\left(\right.$ ITUCEG $^{72}: \mathrm{C}-\mathrm{H} \ldots \mathrm{O}: \mathrm{O} \ldots \mathrm{H}=3.00 \AA, \rho_{\mathrm{bcp}} 0.017 \mathrm{e} \AA^{-3}$ and $\nabla^{2} \rho_{\text {bcp }} 0.23$ e $\AA^{-5}$ ). Molecular graphs and topological values for all bcps found in these structures are given in Figure S15.

Bifurcated hydrogen bonding. The analysis on acceptor ability of O...O system reveals that a significant percent of the investigated crystal structures forms bifurcated hydrogen bonding (in further text BFHB). Similar observation was previously reported by Steiner $^{4}$ where the interaction of the $\mathrm{O}-\mathrm{H}$ donor with the $\mathrm{DMB}$ was described as preferentially bifurcated, involving a single $\mathrm{O}-\mathrm{H}$ donor and both $\mathrm{O}$ centers. Here we performed the statistical CSD analysis in order to estimate the frequency and preferable geometry of BFHB interactions with the O... $\mathrm{O}$ system.

In our initial subset of 1477 crystal structures with D-H...O interactions there are 1050 structures with at least one BFHB. In latter structures, we have found 1646 donor groups involved in BFHB defined by the conditions equivalent to those used in general analysis i.e. both O...H distances $\leq 3.0 \AA$ and both $\mathrm{D}-\mathrm{H} . . . \mathrm{O}$ angles $\geq 110^{\circ}$. Hence, there is more than $70 \%$ of the structures $(1050 / 1477)$ forming the bifurcated HB, and there are cases with more than one BFHB per O...O system.

Our statistical analysis on BFHB with O...O system resulted in following conclusions:

(a) although considerable fraction of interactions belongs to BFHB (especially at short distances), the majority of interactions with O...O system does not belong to the BFHB. This is evident from the scatterplot O1a...H vs. O1b...H in Figure S16 which shows higher number of interactions with only one O...H contact shorter than $3 \AA$, in comparison to those where a single $\mathrm{H}$ atom interacts with both $\mathrm{O}$ acceptors; (b) BFHB shows somewhat higher tendency to place interacting $\mathrm{H}$ atom in the level of $\mathrm{O} . . . \mathrm{O}$ plane. This is evidenced from the $\mathrm{d}(\mathrm{H} . . . \mathrm{P} 1)$ histogram in Figure S17 (analogue to Figure 5) showing the position of the H atoms from the BFHB with regard to $\mathrm{O} \ldots \mathrm{O}$ acceptor plane; (c) scaterplot $\mathrm{D}-\mathrm{H} . . \mathrm{O} 1 \mathrm{a}$ vs. D-H...O1b displaying the 
interaction angles in BFHB (Figure S18) shows the dominance of interactions where the sum of these angles is approximately $295^{\circ}$; (d) among 140 crystal structures containing the $\mathrm{O}-\mathrm{H} . . \mathrm{O}$ or $\mathrm{N}-\mathrm{H}$... O interactions there are 121 structures forming the BFHB by means of 136 donor groups. Hence, almost each crystal structure from this subset forms $\mathrm{O}-\mathrm{H} \ldots \mathrm{O}$ or $\mathrm{N}-\mathrm{H} \ldots \mathrm{O}$ BFHB; (e) in comparison to a whole interaction set, the BFHB shows higher tendency toward shorter O...H contacts. This is evidenced from the histogram in Figure S19 which shows that BFHB represent a largest fraction (of the total number of interactions) at short contacts; (f) conditions less restrained do not lead to significant changes in statistics of BFHB. Thus, when the two interaction angles are restrained to $\mathrm{D}-\mathrm{H} \ldots \mathrm{O} \geq 100^{\circ}$, the number of structures with $\mathrm{BFHB}$ increases to 1117 (from the initial 1050).

\section{Effect of substituents on the acceptor ability of $0 . . .0$ system}

As mentioned in previous section, the contribution of CSD structures containing the alkoxy substituents other than methoxy is low. Among the 1477 crystal structures containing the fragment (Figure 1) and forming the D-H...O interactions there are only 255 structures where $\mathrm{Z}$ atom attached to $\mathrm{C} 1$ is non-H atom. These structures form $670 \mathrm{D}-\mathrm{H} \ldots \mathrm{O}$ interactions, hence less than three interaction per structure (over five is found for dimethoxy structures). Though the corresponding oxygen acceptor can generate the EP with properties similar to the dimethoxy compounds (Figure S10) the voluminous substituents seem to reduce the number of donors able to approach the O...O system which reflects in lower number of interactions.

Since the smaller alkoxy groups enabled greater number of interactions with the corresponding O...O acceptors, we have also checked the behavior of structural fragments containing the hydroxy instead of alkoxy groups attached to C3 atoms (Figure 1), and also the behavior of 
fragments containing the asymmetric hydroxy-alkoxy binding sites. Nevertheless, due to a decreased uniformity and predictability of such fragments, they were not included in our final statistical analysis. Namely, these systems frequently form intramolecular $\mathrm{O}-\mathrm{H} \ldots \mathrm{O}$ hydrogen bond which significantly changes the EP distribution of the O...O acceptor site, and disables the structural (and electrostatic) predictability (Figures S20, S21). The number of structures where one or both substituents are hydroxyl groups is smaller than the number of structures with alkoxy substituents, however in the absence of intramolecular interaction these compounds display similar EP features of the corresponding O...O acceptor site (Figures S20, S21), and deserve attention as efficient $\mathrm{H}$-acceptors.

Recently there have been a number of studies where the ortho-methoxy-hydroxy group is recognized as an efficient halogen bonding acceptor capable of forming several different halogen-bonded motifs. ${ }^{73-75}$ One can expect that the capability of this acceptor site for halogen bonding also emerges from the strongly negative electrostatic potential generated by the pair of oxygen atoms (Figure S21). The EP features of hydroxy-alkoxy sites seem similar to those of more symmetric alkoxy-alkoxy sites. The asymmetry of the hydroxy-alkoxy site is reflected in a slight shifting of the EP minima toward the oxygen acceptor from the hydroxy group as well as in somewhat larger EP isosurfaces generated at this side of an O...O system. This is in accordance with a slightly more negative charge found for the hydroxy oxygen of such system. ${ }^{74}$

Finally, we have checked the behavior of the structural fragments containing the additional, non-H substituent attached to $\mathrm{C} 4$ atoms (Figure 1). Again, due to a decreased uniformity and predictability of such fragments, they were not included in our final statistical analysis. Namely, the geometry of these fragments noticeably differs, the distance between the O1a...O1b atoms increases, while the alkoxy substituent vicinal to substituted C4 is no longer coplanar with the 
phenyl ring. The average number of interactions to corresponding $\mathrm{O} \ldots \mathrm{O}$ acceptor pairs decreases below three. Though oxygen atoms still generate a significantly negative EP the form of the isopotential surface in these structures is not uniform and predictable as in the case of fragment without the additional $\mathrm{C} 4$ substituents.

\section{Geometry, ab initio estimate of the interaction energy and description of bonding in the DMB-H ${ }_{2} \mathrm{O}$ dimer based on EDA and ETS-NOCV methods}

The previous results on $\mathrm{DMB}^{33}$ show that the conformer having the $\mathrm{C} 2 \mathrm{v}$ symmetry is to be lowest in energy, except for the MP2/6-31G(d) method, which gives a slightly lower energy for the $\mathrm{C} 2$ conformer. We performed a full geometry optimization of the $\mathrm{C} 2 \mathrm{v}$ conformer at the B3LYP/aug-cc-pVTZ level of theory and got a good agreement between the structural parameters and the experimental results obtained by gas-phase electron diffraction (GED) ${ }^{33}$ (Table S1). The results confirmed the C2v symmetry of DMB. It can be noticed that DMB is characterized by a short O...O distance $(2.593 \AA)$ as well as by the shrinking of the O1a-C3a$\mathrm{C} 3 \mathrm{~b}$ and $\mathrm{O} 1 \mathrm{~b}-\mathrm{C} 3 \mathrm{~b}-\mathrm{C} 3 \mathrm{a}$ angles (both angles are $115^{\circ}$ ) and the corresponding extension of the $\mathrm{C} 4 \mathrm{a}-\mathrm{C} 3 \mathrm{a}-\mathrm{O} 1 \mathrm{a}$ and $\mathrm{C} 4 \mathrm{~b}-\mathrm{C} 3 \mathrm{~b}-\mathrm{O} 1 \mathrm{~b}$ angles (both angles are $125^{\circ}$ ). This is in accordance with the fact that highest occupied molecular orbital (HOMO) of DMB is highly delocalized towards two methoxy oxygen atoms (Figure S22).

The study of the rotationally resolved $\mathrm{S} 1 \leftarrow \mathrm{S} 0$ electronic spectra of DMB suggests that the water molecule is attached via two $\mathrm{O}-\mathrm{H}$... $\mathrm{O}$ hydrogen bonds to the methoxy groups in both electronic states. ${ }^{28}$ The authors suggested that the hydrogens of the attached water molecule are most probably hydrogen bonded to lone pairs of electrons that belong to the methoxy oxygens pointing above and below the symmetry plane of the DMB molecule. According to the analysis presented in that study, the water molecule lies well outside the two methoxy groups at a 
distance of about $4.05 \AA$ from the center of mass of the DMB molecule. Torsional subbands that appear in the spectrum of $\mathrm{DMB}-\mathrm{H}_{2} \mathrm{O}$ show that the attached water molecule moves within the complex from one set of lone pairs to the other.

We performed a full geometry optimization of the DMB- $\mathrm{H}_{2} \mathrm{O}$ dimer employing the MP2 method and aug-cc-pVDZ basis set. Additional geometry optimizations at the B3LYP/6$311+\mathrm{G}(\mathrm{d}, \mathrm{p}), \mathrm{B} 3 \mathrm{LYP} / 6-311++\mathrm{G}(\mathrm{d}, \mathrm{p})$, and $\omega \mathrm{BP} 97 \mathrm{X}-\mathrm{D} /$ aug-cc-pVDZ levels of theory were also performed in order to test the effect of method and basis sets on the optimized structures. The optimized equilibrium geometry of the $\mathrm{DMB}-\mathrm{H}_{2} \mathrm{O}$ dimer in the ground electronic state is presented in Figure 7a. Our values of the rotational constants are in good agreement with the experimental values obtained from the rotationally resolved electronic spectrum of the DMB$\mathrm{H}_{2} \mathrm{O}$ dimer $^{28}$, Table 1. It should be noticed that our calculated values are equilibrium rotational constants while experimental values are vibrationally averaged values.

The optimized geometry of the DMB- $\mathrm{H}_{2} \mathrm{O}$ dimer shows that in minimum energy structure (Figure 7a) one of the hydrogen atoms $(\mathrm{H} 1)$ of the water molecule forms a hydrogen bond with both methoxy oxygens so that $\mathrm{O}-\mathrm{H} 1$ bond is almost in the plane of the aromatic plane of the DMB molecule Figure S23). The second hydrogen $(\mathrm{H} 2)$ is below the aromatic plane and is at a longer distance from the nearest methoxy oxygen than the H1. Position of water donor in optimized system coincides with the EP minimum and agrees with the fact that the shortest CSD interactions are preferentially bifurcated. Some selected structural parameters of the DMB- $\mathrm{H}_{2} \mathrm{O}$ dimer are collected in Table 1 . The topological analysis ${ }^{43}$ of electron density located two bond critical points for the optimized DMB- $\mathrm{H}_{2} \mathrm{O}$ dimer (Figure 7b), confirming the bifurcated hydrogen bonding between the components $\left[b c p_{1}: D_{\mathrm{H} \ldots \mathrm{O}} 2.04 \AA ; \rho_{\mathrm{bcp}} 0.131 \mathrm{e} \AA^{-3} ; \nabla^{2} \rho_{\mathrm{bcp}} 1.61 \mathrm{e} \AA^{-}\right.$ ${ }^{5} ; b c p_{2}: D_{\mathrm{H} \ldots \mathrm{o}} 2.39 \AA ; \rho_{\text {bcp }} 0.062$ e $\AA^{-3} ; \nabla^{2} \rho_{\text {bcp }} 0.86$ e $\left.\AA^{-5}\right]$. 




(a)

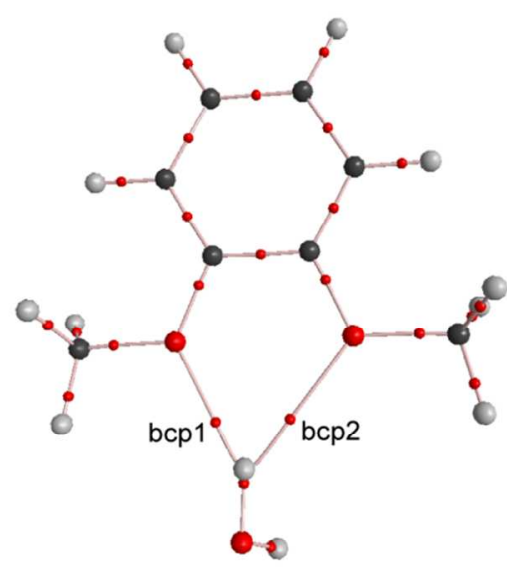

(b)

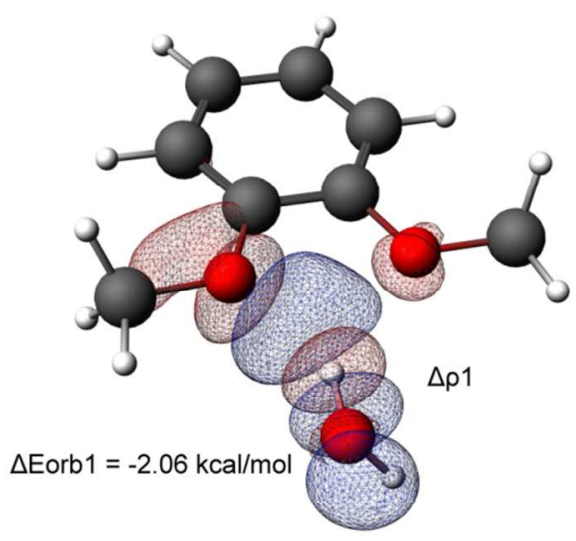

(c)

Figure 7. (a) Optimized geometry of the DMB- $\mathrm{H}_{2} \mathrm{O}$ dimer computed at the MP2/aug-cc-pVDZ level of theory; (b) Molecular graph of the system showing the corresponding bond critical points; (c) Contour plot of the most important deformation density charge transfer channel $\left(\Delta \rho_{1}\right)$ describing the interaction between water and the DMB molecule. Charge accumulation due to the DMB- $\mathrm{H}_{2} \mathrm{O}$ interaction is given in blue color, charge depletion is in red color. Also shown is the corresponding energy contribution, $\Delta E_{\text {orbl }}$, (in $\mathrm{kcal} / \mathrm{mol}$ ) obtained at the BP86-D/TZ2P level of theory.

Table 1 Selected structural parameters, distances $(\AA)$ and bond angles $\left(^{\circ}\right)$, rotational constants (cm-1) obtained at the MP2/aug-cc-pVDZ level of theory, and estimate of binding energy ( $\mathrm{kcal} / \mathrm{mol}$ ) in the $\mathrm{DMB}-\mathrm{H}_{2} \mathrm{O}$ dimer

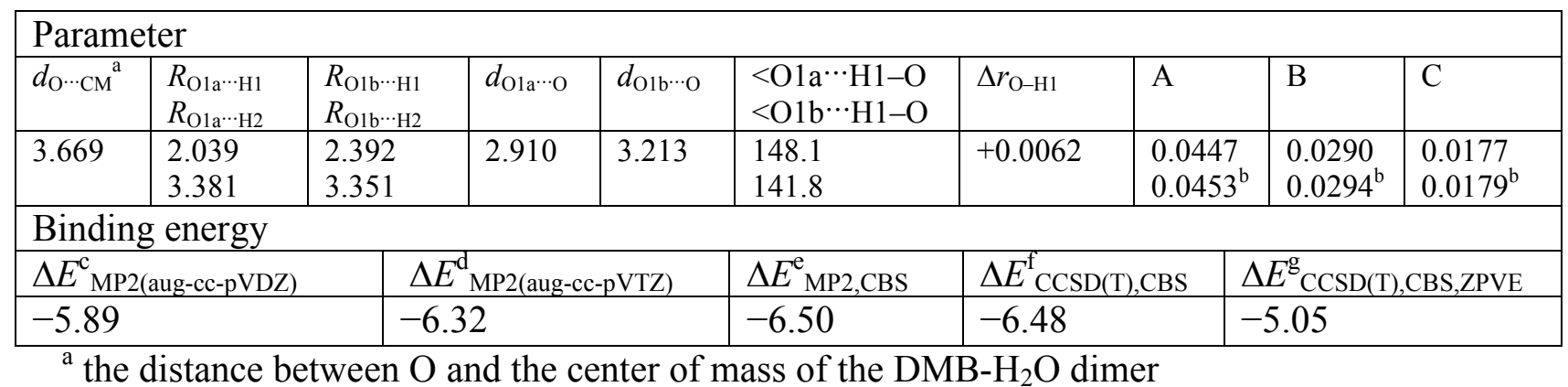


The anisole- $\mathrm{H}_{2} \mathrm{O}$ dimer has been investigated in several experimental and theoretical studies. ${ }^{34-}$ ${ }^{39}$ The equilibrium geometry of the $\mathrm{H}_{2} \mathrm{O}$ molecule in the DMB- $\mathrm{H}_{2} \mathrm{O}$ dimer, which we presented in this paper, shows a resemblance with the $\mathrm{H}_{2} \mathrm{O}$ geometry in the anisole- $\mathrm{H}_{2} \mathrm{O}$ dimer proposed by Becucci et al. ${ }^{34}$ Our best estimate value of the interaction energy between DMB and water obtained from $\operatorname{CCSD}(\mathrm{T})$ calculations along with the BSSE and CBS corrections is $\Delta E_{\mathrm{CCSD}(\mathrm{T}), \mathrm{CBS}}$ $=-6.5 \mathrm{kcal} / \mathrm{mol}$. For the anisole-water dimer Barone et al. ${ }^{35}$ obtained by similar $\operatorname{CCSD}(\mathrm{T})$ calculations the interaction energy of $-4.2 \mathrm{kcal} / \mathrm{mol}$. Owing to the existence of two methoxy groups in DMB- $\mathrm{H}_{2} \mathrm{O}$ there is an increase of the interaction energy of more than $50 \%$ compared to the interaction energy in the anisole- $\mathrm{H}_{2} \mathrm{O}$ dimer.

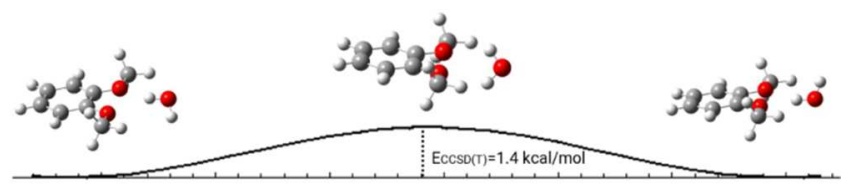

Figure 8. The barrier between minimum energy structure of the $\mathrm{DMB}-\mathrm{H}_{2} \mathrm{O}$ dimer and the transition energy structure calculated at the $\operatorname{CCSD}(\mathrm{T}) /$ aug-cc-pVDZ level employing the B3LYP/6-311++G(d,p) optimized structures of the minimum and transition state structures. 
Pasquini et $a l .{ }^{38}$ in their extensive study based on theoretical investigation and resonance enhanced multiphoton ionization and rotationally resolved electronic spectra of the anisole- $\mathrm{H}_{2} \mathrm{O}$ have highlighted the complexity of the potential energy surface in this dimer. The authors pointed out to the extremely flat PES in the region between anisole oxygen and the aromatic hydrogen. ${ }^{38}$ In our study, the unconstrained geometry optimization of the transition state in DMB-H2O dimer leads to a transition state structure where each of the water H-atoms interacts with one of the methoxy oxygens, Figure 8, Figure S24). It is interesting that the reorientation of the water molecules from minimum toward the transition state structure occurs with a rather low energy barrier of only $E_{\mathrm{CCSD}(\mathrm{T})}=1.4 \mathrm{kcal} / \mathrm{mol}$. The barrier was obtained at the $\mathrm{CCSD}(\mathrm{T}) /$ aug-ccpVDZ level of theory and was calculated at the minimum and transition state structures optimized at the B3LYP/6-311++G(d,p) level.

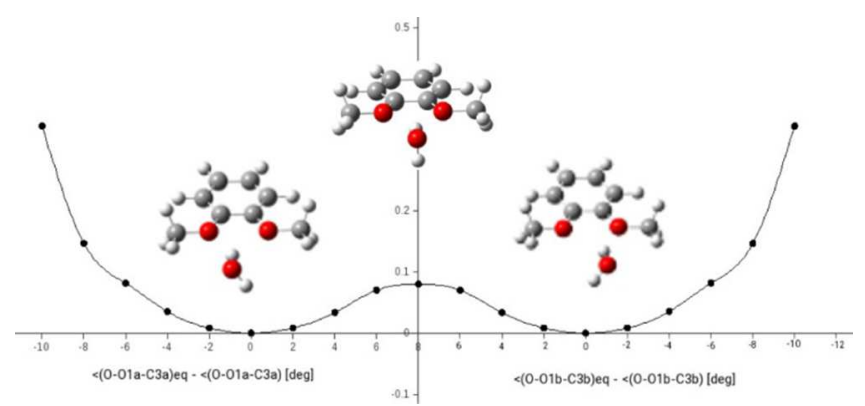

Figure 9. Potential energy path of $\mathrm{DMB}-\mathrm{H}_{2} \mathrm{O}$ dimer in the ground electronic state as a function of a water in-plane bending coordinate. Energies from constrained geometry optimization obtained at the B3LYP/6-311+G(d,p) level are presented. The two minima arise from two equivalent orientations of the $\mathrm{H}_{2} \mathrm{O}$ molecule.

Figure 9 shows potential energy paths for the in-plane bending motion of water from a minimum energy structure toward central region between two methoxy oxygens. There are four 
minima that arise from equivalent orientations of the attached $\mathrm{H}_{2} \mathrm{O}$ with respect to the DMB moiety. The results show that as the in-plane bending angle $\mathrm{O}-\mathrm{O} 1 \mathrm{a}-\mathrm{C} 3 \mathrm{a}$ (or $\mathrm{O}-\mathrm{O} 1 \mathrm{~b}-\mathrm{C} 3 \mathrm{~b}$ ) is more deviate from the minimum structure toward the central region, the energy raises very slowly indicating a very flat potential energy surface in the region between methoxy oxygens. Taking into account the flat PES surface and the small energy barrier between the minima and transition state it can be suggested that the attached water molecule undergoes a large amplitude motion between two methoxy oxygens and that $\mathrm{DMB}-\mathrm{H}_{2} \mathrm{O}$ complex shows high flexibility. This is in accordance with the experimental results $^{28}$, also proposing the mobility of the water molecule between the methoxy oxygen acceptors.

Since DMB can take part in different intermolecular interactions, a balance of different terms can be assumed in the DMB- $\mathrm{H}_{2} \mathrm{O}$ dimer. The previous results show that EDA and ETS-NOCV methods can give valuable information on different types of bonding. According to the results of the EDA analysis of DMB- $\mathrm{H}_{2} \mathrm{O}$ system (Table 2), the most important contribution in a stabilization of the DMB- $\mathrm{H}_{2} \mathrm{O}$ complex comes from the electrostatic attraction $\left(\Delta E_{\text {elstat }}\right)$ which is in accordance with our analysis of the electrostatic potential. The electrostatic term is more than three times larger than the dispersion term. The additional stabilization, $\Delta E_{\text {orb }}$, stems from stabilizing interactions between the occupied molecular orbitals on one fragment with the unoccupied molecular orbitals of another fragment or by mixing of occupied and virtual orbitals within the same fragment. It can be noticed that $\Delta E_{\text {orb }}$ is smaller than $\Delta E_{\text {elstat }}$ but it is larger than $\Delta \mathrm{E}_{\mathrm{disp}}$. Each methoxy group oxygen has two lone pairs of electrons pointing above and below the horizontal plane of the DMB molecule. The leading NOCV-based deformation density channel presented in Figure $7 \mathrm{c}$ shows a charge transfer of the type $\mathrm{p}\left(\mathrm{O}_{\text {methoxy }}\right) \rightarrow \sigma^{*}(\mathrm{O}-\mathrm{H})$. We found that 
based on NOCV deformation density contours the oxygen of the methoxy group is capable of forming hydrogen bonding.

Table 2 ETS-NOCV energy decomposition ( $\mathrm{kcal} / \mathrm{mol}$ ) for the DMB- $\mathrm{H}_{2} \mathrm{O}$ system obtained at the BP86-D/TZ2P level of theory

\begin{tabular}{|l|c|l|l|l|l|}
\hline dimer & $\Delta E_{\text {orb }}$ & $\Delta E_{\text {elstat }}$ & $\Delta E_{\text {Pauli }}$ & $\Delta E_{\text {disp }}$ & $\Delta E_{\text {total }}$ \\
\hline DMB- $_{2} \mathrm{O}$ & -3.34 & -7.85 & 7.03 & -2.24 & -6.40 \\
\hline
\end{tabular}

\section{Hydrogen bond interactions of DMB in systems with several donors}

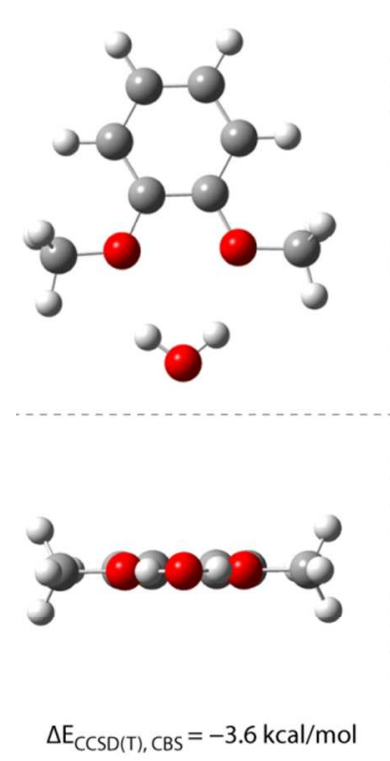

(a)
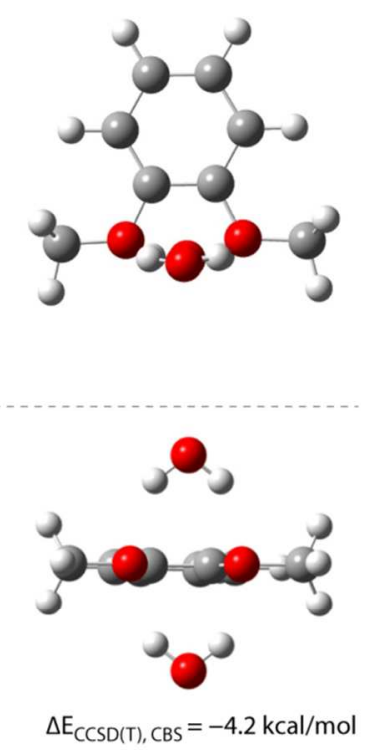

(b)

Figure 10 DMB- $\mathrm{H}_{2} \mathrm{O}$ model systems used for the $a b$ initio calculations and the corresponding interaction energies. Two orthogonal projections of: (a) dimer and (b) trimer.

The above CSD analysis showed that up to eight donors can simultaneously interact with O...O fragment and that a number of contacts exists not only in the equatorial plane (i.e. level of P1, Figure 5) but also above and below the plane. To estimate and compare the efficiency of the O...O system in the case of equatorial and axial interactions we performed $a b$ initio calculations 
on two additional model systems. In the model system A (Figure 10a) the water molecule is in the equatorial plane while in the model system B (Figure 10b) one water molecule is above the aromatic plane and another water molecule is below the plane. Each water molecule is here assumed to form two $\mathrm{O}-\mathrm{H}$... $\mathrm{O}$ interactions by engaging both $\mathrm{H}$ donors towards the methoxy acceptors. To provide comparison on the same ground, all water molecules display equivalent geometry with respect to the O...O system, with all H...O distances fixed to $2.0 \AA$ (chosen as preferable distance from the optimized DMB- $\mathrm{H}_{2} \mathrm{O}$ system). The interaction energy of the model system $\mathrm{A}$ is $\Delta E_{\mathrm{CCSD}(\mathrm{T}), \mathrm{CBS}}=-3.63 \mathrm{kcal} / \mathrm{mol}$ while the interaction energy of the model system $\mathrm{B}$ is $\Delta E_{\mathrm{CCSD}(\mathrm{T}), \mathrm{CBS}}=-4.21 \mathrm{kcal} / \mathrm{mol}$. The results of $a b$ initio calculations indicate that $\mathrm{DMB}$ can build hydrogen bonds with two water molecules simultaneously and that the bonding can be achieved in the space above and below the aromatic plane, which is in the agreement with the results from the CSD search.

\section{Conclusion}

A Cambridge Structural Database analysis presented in this study reveals highly predictable structural features of the $o$-dialkoxybenzene fragment comprising two ether oxygen acceptors in ortho positions of benzene ring. The consistence in fragment conformation leads to a predictable shape, spatial distribution and magnitude of the negative electrostatic potential and thus to a predictable interaction of the system in different crystalline environments. Short intramolecular nonbonded contact between an oxygen pair $(2.57 \AA$ in average) generates a wide hydrogen bonding acceptor area able to simultaneously accommodate up to eight hydrogen bonding donors in which $\mathrm{O} \ldots \mathrm{H} \leq 3.0 \AA$ and $\mathrm{D}-\mathrm{H} . . . \mathrm{O} \geq 110^{\circ}$. Nearly $80 \%$ of the extracted structures forms the interactions where $\mathrm{O} \ldots \mathrm{H} \leq 2.6 \AA$. This is substantially higher percent in comparison to the 
anisole fragment containing structures with the similar interactions (ca. 50\%) and indicates a significantly improved acceptor ability gained through the O...O acceptors cooperativity. The donor groups are symmetrically distributed around the O...O system and similarly populate the wide region influenced by the negative EP. Considerable fraction of interactions, especially at short distances, belongs to bifurcated hydrogen bonds. Topological analysis confirms the relevance and attractive role of the long distance interactions.

The results of ab initio calculations for the DMB- $\mathrm{H}_{2} \mathrm{O}$ dimer show that extremely flat potential energy surface between equivalent minima allows the $\mathrm{H}_{2} \mathrm{O}$ molecule to exhibit in-plane motion very easily. When one assumes that $\mathrm{H}_{2} \mathrm{O}$ can also perform out-of-plane motion between minima with very small energy barrier of only $E_{\mathrm{CCSD}(\mathrm{T})}=1.4 \mathrm{kcal} / \mathrm{mol}$, the $\mathrm{DMB}$ molecule enables the water molecule to move easily between two binding sites formed by two methoxy oxygens. The description of bonding based on EDA and ETS-NOCV methods shows that O...O system in DMB is capable of forming hydrogen bonds with dominance of electrostatic component ( $\Delta E_{\text {elstat }}$. Moreover, DMB can interact with molecules that are placed above and below the aromatic plane. Based on that, it can be anticipated that in different external confinements, DMB can offer similar wide interaction area for building hydrogen bonds.

In summary, owing to the broad EP surface between two methoxy oxygens of DMB, the DMB- $\mathrm{H}_{2} \mathrm{O}$ interaction energy of $-6.5 \mathrm{kcal} / \mathrm{mol}$ (stronger than in the anisole- $\mathrm{H}_{2} \mathrm{O}$ dimer), large number of contacts from the CSD search in the $\mathrm{O} \ldots \mathrm{O}$ region and up to eight $\mathrm{H}$-donors per DMB moiety from the database, it can be concluded that the system of two DMB oxygen acceptors is characterized by a cooperativity, significant hydrogen bond capacity, and can be regarded as a good hydrogen bond acceptor site. The present results also point to the predictable distribution and high value of negative EP. This information can be useful for molecular recognition 
processes considering the potential biological significance of the $o$-dialkoxybenzene containing compounds. Due to small number of structures and decreased structural uniformity and electrostatic predictability of the fragments containing the hydroxyl instead of alkoxy groups, these were not included in the present statistical analysis. However in the absence of intramolecular hydrogen bonding the compounds containing the hydroxyl groups generate a similar uniform EP area around the corresponding O...O acceptor site, and deserve attention as efficient $\mathrm{H}$-acceptors.

\section{Acknowledgments}

We acknowledge the financial support of the Ministry of Education, Science and Technological Development (MESTD) of the Republic of Serbia (contract No. ON172014, ON172035, ON172001). We are thankful to the colleagues from the Scientific Computing Laboratory of the Institute of Physics in Belgrade for the support and help. Numerical simulations were run on the PARADOX cluster at the Scientific Computing Laboratory of the Institute of Physics Belgrade, supported in part by MESTD of the Republic of Serbia under project No. ON171017. We are grateful to Dr. P. R. Bunker for many enlightening discussions on the subject of DMB- $\mathrm{H}_{2} \mathrm{O}$ and Prof. D. W. Pratt for providing us with valuable comments from the experimental study on the DMB- $\mathrm{H}_{2} \mathrm{O}$ dimer. B.O. acknowledges the using of the Gaussian program (project No. ON1720035). 


\section{Supporting Information}

CSD refcodes, additional plots from the CSD search: distribution of relevant distances, torsion and dihedral angles. EP distribution within different crystal structures containing the $o$ dialkoxybenzene fragment; Examples of crystal structures with multiple hydrogen bonding interactions to O...O systems.

\section{References:}

(1) Jeffrey, G. A. An Introduction to Hydrogen Bonding; Oxford University Press: Oxford, 1997.

(2) Desiraju, G. R.; Steiner, T. The Weak Hydrogen Bond in Structural Chemistry and Biology; Oxford University Press: Oxford, 2001.

(3) Tiekink, E. R.; Vittal, J.; Zaworotko M. (Eds.). Organic Crystal Engineering: Frontiers in Crystal Engineering; Wiley Ltd. publications, 2010.

(4) Steiner, T. Angew. Chem. Int. Ed. 2002, 41, 48-76.

(5) Allen, F. H. Acta Crystallogr., Sect. B: Struct. Sci. 2002, 58, 380-388.

(6) Desiraju, G. R. Crystal Engineering: The Design of Organic Solids; Elsevier: Amsterdam, 1989.

(7) Dunitz, J. D.; Gavezzotti, A. Angew. Chem. Int. Ed. 2005, 44, 1766-1787.

(8) Thakur, T. S.; Dubey, R.; Desiraju, G. R. Annu. Rev. Phys. Chem. 2015, 66, 21-42.

(9) Woodley, S. M.; Catlow, R. Nature mater. 2008, 937-946. 
(10) Zhang, L.; Liu, F.; Guo, Y.; Wang, X.; Guo, J.; Wei, Y.; Chen, Z; Sun, D. Cryst. Growth Des. 2012, 12, 6215-6222.

(11) Ahmad, R.; Hardie, M. J. Cryst. Growth Des. 2003, 3, 493-499.

(12) Collas, A.; Bagrowska, I.; Aleksandrzak, K.; Zeller, M.; Blockhuys, F. Cryst. Growth Des. 2011, 11, 1299-1309.

(13) Geng, N.; Chen, J. M.; Li, Z. J.; Jiang, L.; Lu, T. B. Cryst. Growth Des. 2013, 13, 35463553.

(14) Payne, R. M.; Oliver, C. L. CrystEngComm, 2016, 18, 7965-7971.

(15) Jha, K. K.; Dutta, S.; Kumar, V.; Munshi, P. CrystEngComm, 2016, 18, 8497-8505.

(16) The Merck Index, fourteenth ed., Merck \& Co., Inc., USA, 2006.

(17) Shamma, M.; Moniot, J. L. Isoquinoline Alkaloids Research, 1972-1977, Plenum Press, New York, 1978.

(18) Ruffolo, R. R.; Gellai, M.; Hieble, J. P.; Willette, R. N.; Nichols, A. J. Eur. J. Clin. Pharm. 1990, 38, S82-S88.

(19) Kong, W.; Wei, J.; Abidi, P.; Lin, M.; Inaba, S.; Li, C.; Wang, Y.; Wang Z.; Si, S.; Pan, S.; Wang, S.; Wu. J.; Wang, Y.; Li, Z.; Liu, J.; Jiang J-D. Nature medicine, 2004, 10, $1344-1351$.

(20) Hamann, S. R.; Todd, G. D.; McAllister Jr, R. G. Pharmacology, 1983, 27, 1-8.

(21) Gokel, G. W.; Leevy, W. M.; Weber, M. E. Chem. Rev. 2004, 104, 2723-2750.

(22) Wishkerman, S.; Bernstein, J.; Hickey, M. B. Cryst. Growth Des., 2009, 9, 3204-3210.

(23) Kusaka, R.; Inokuchi, Y.; Ebata, T. Phys. Chem. Chem. Phys. 2008, 10, 6238-6244.

(24) Lommerse, J. P. M.; Price, S. L.; Taylor R. J. Comput. Chem. 1997, 18, 757-774.

(25) Berthelot, M.; Besseau, F.; Laurence, C. Eur. J. Org. Chem. 1998, 925-931. 
(26) Rathore, R. S.; Alekhya, Y.; Kondapi A. K.; Sathiyanarayanan, K. CrystEngComm, 2011, 13, 5234-5238.

(27) Laurence, C.; Berthelot M. Perspect. Drug Discovery Des. 2000, 18, 39-60.

(28) Yi, J. T.; Ribblett, J. W. ; Pratt, D. W. J. Phys. Chem. A, 2005, 109, 9456-9464.

(29) Esrafili, M. D., Mohammadian-Sabet, F. Chem.Phys. Lett. 2015, 634, 210-215.

(30) Novák, M., Foroutan-Nejad, C., \& Marek, R. Phys.Chem.Chem.Phys. 2015, 17, $6440-6450$.

(31) Suvitha, A., Periandy, S., Gayathri, P. Spectrochim. Acta, Part A: Molecular and Biomolecular Spectroscopy, 2015, 138, 357-369.

(32) Varfolomeev, M. A., Abaidullina, D. I., Solomonov, B. N., Verevkin, S. P., Emelyanenko, V. N. J. Phys. Chem. B, 2010, 114 16503-16516.

(33) Dorofeeva, O. V.; Shishkov, I. F.; Karasev, N. M.; Vilkov, L. V.; Oberhammer, H. J. Molec. Struc. 2009, 933, 132-141.

(34) Becucci, M.; Pietraperzia, G.; Pasquini, M.; Piani, G.; Zoppi, A.; Chelli, R.; Castellucci, E.; Demtroeder W. J. Chem. Phys. 2004, 120, 5601- 5607.

(35) Barone, V.; Biczysko, M.;Pavone, M. Chem. Phys. 2008, 346, 247-256.

(36) Reimann, B.; Buchhold, K.; Barth, H.-D.; Brutschy, B.; Tarakeshwar, P.; Kwang S. K. J. Chem. Phys. 2002, 117, 8805-8822.

(37) Giuliano, B. M.; Caminati, W. Angew. Chem. Int. Ed. 2005, 44, 603 -606. 
(38) Pasquini, M.; Schiccheri, N.; Piani, G.; Pietraperzia, G.; Becucci, M.; Biczysko, M.; Pavone, M.; Barone, V. J. Phys. Chem. A 2007, 111, 12363-12371.

(39) Ribblett, J. W.; Sinclair, W. E.; Borst, D. R.; Yi, J. T.; Pratt, D. W. J. Phys. Chem. A 2006, $110,1478-1483$.

(40) Tsuzuki, S.; Houjou, H.; Nagawa, Y.; Hiratani, K. J. Chem. Soc., Perkin Trans. 2, 2002, $1271-1273$.

(41) Raghavachari, K.; Trucks, G.W.; Pople, J.A.; Head-Gordon, M. Chem. Phys. Lett. 1989, $157,479-483$.

(42) Politzer, P.; Truhlar, D. G. Chemical Applications of Atomic and Molecular Electrostatic Potentials; Plenum: New York, 1981.

(43) Bader, R. F. W. Atoms-in-Molecules: A Quantum Theory, Clarendon, Oxford, 1990.

(44) Bruno, I. J.; Cole, J. C.; Lommerse, J. P. M.; Rowland, R. S.; Taylor, R.; Verdonk, M. L. J. Comput. Aid. Mol. Des. 1997, 11, 525-537.

(45) Frisch, M. J.; Trucks, G. W.; Schlegel, H. B.; Scuseria, G. E.; Robb, M. A.; Cheeseman, J. R.; Montgomery, Jr., J. A.; Vreven, T.; Kudin, K. N.; Burant, J. C.; Millam, J. M.; Iyengar, S. S.; Tomasi, J.; Barone, V.; Mennucci, B.; Cossi, M.; Scalmani, G.; Rega, N.; Petersson, G. A.; Nakatsuji, H.; Hada, M.; Ehara, M.; Toyota, K.; Fukuda, R.; Hasegawa, J.; Ishida, M.; Nakajima, T.; Honda, Y.; Kitao, O.; Nakai, H.; Klene, M.; Li, X.; Knox, J. E.; Hratchian, H. P.; Cross, J. B.; Bakken, V.; Adamo, C.; Jaramillo, J.; Gomperts, R.; Stratmann, R. E.; Yazyev, O.; Austin, A. J.; Cammi, R.; Pomelli, C.; Ochterski, J. W.; Ayala, P. Y.; Morokuma, K.; Voth, G. A.; Salvador, P.; Dannenberg, J. J.; Zakrzewski, V. G.; Dapprich, S.; Daniels, A. D.; Strain, M. C.; Farkas, O.; 
Malick, D. K.; Rabuck, A. D.; Raghavachari, K.; Foresman, J. B.; Ortiz, J. V.; Cui, Q.; Baboul, A. G.; Cli ff ord, S.; Cioslowski, J.; Stefanov, B. B.; Liu, G.; Liashenko, A.; Piskorz, P.; Komaromi, I.; Martin, R. L.; Fox, D. J.; Keith, T.; Al-Laham, M. A.; Peng, C. Y.; Nanayakkara, A.; Challacombe, M.; Gill, P. M. W.; Johnson, B.; Chen, W.; Wong, M. W.; Gonzalez, C.; Pople, J. A. Gaussian 09, Revision C.02; Gaussian, Inc.: Wallingford, CT, 2004.

(46) Biegler-König, F. Schönbohm, J. AIM2000 - A program to Analyze and Visualize Atoms in Molecules, Vers. 2, Bielefeld (Germany) 2002.

(47) Volkov, A.; Macchi, P.; Farrugia, L. J.; Gatti, C.; Mallinson, P.; Richter, T.; Koritsanszky, T. XD2006: A Computer Program Package for Multipole Refinement, Topological Analysis of Charge Densities and Evaluation of Intermolecular Energies from Experimental and Theoretical Structure Factors; 2006.

(48) Volkov, V.; Koritsanszky, T.; Chodkiewicz, M.; King, H. F. J. Comput. Chem. 2009, 30, $1379-1391$.

(49) Boys, S.F.; Bernardi, F. Mol. Phys. 1970, 19, 553-566.

(50) Møller, C.; Plesset, M.S. Phys. Rev. 1934, 46, 618-622.

(51) Gaussian 03, Revision C.02, Frisch, M. J.; Trucks, G. W.; Schlegel, H. B.; Scuseria, G. E.; Robb, M. A.; Cheeseman, J. R.; Montgomery, Jr., J. A.; Vreven, T.; Kudin, K. N.; Burant, J. C.; Millam, J. M.; Iyengar, S. S.; Tomasi, J.; Barone, V.; Mennucci, B.; Cossi, M.; Scalmani, G.; Rega, N.; Petersson, G. A.; Nakatsuji, H.; Hada, M.; Ehara, M.; Toyota, K.; Fukuda, R.; Hasegawa, J.; Ishida, M.; Nakajima, T.; Honda, Y.; Kitao, O.; Nakai, H.; Klene, M.; Li, X.; Knox, J. E.; Hratchian, H. P.; Cross, J. B.; Bakken, V.; Adamo, C.; Jaramillo, J.; Gomperts, R.; 
Stratmann, R. E.; Yazyev, O.; Austin, A. J.; Cammi, R.; Pomelli, C.; Ochterski, J. W.; Ayala, P. Y.; Morokuma, K.; Voth, G. A.; Salvador, P.; Dannenberg, J. J.; Zakrzewski, V. G.; Dapprich, S.; Daniels, A. D.; Strain, M. C.; Farkas, O.; Malick, D. K.; Rabuck, A. D.; Raghavachari, K.; Foresman, J. B.; Ortiz, J. V.; Cui, Q.; Baboul, A. G.; Clifford, S.; Cioslowski, J.; Stefanov, B. B.; Liu, G.; Liashenko, A.; Piskorz, P.; Komaromi, I.; Martin, R. L.; Fox, D. J.; Keith, T.; AlLaham, M. A.; Peng, C. Y.; Nanayakkara, A.; Challacombe, M.; Gill, P. M. W.; Johnson, B.; Chen, W.; Wong, M. W.; Gonzalez, C.; and Pople, J. A.; Gaussian, Inc., Wallingford CT, 2004.

(52) Werner, H.-J.; Knowles, P. J.; Knizia, G.; Manby, F. R.; Schütz, M.; Celani, P.; Korona, T.; Lindh, R.; Mitrushenkov, A.; Rauhut, G.; Shamasundar, K. R.; Adler, T. B.; Amos, R. D.; Bernhardsson, A.; Berning, A.; Cooper, D. L.; Deegan, M. J. O.; Dobbyn, A. J.; Eckert, F.; Goll, E.; Hampel, C.; Hesselmann, A. ; Hetzer, G.; Hrenar, T.; Jansen, G.; Köppl, C.; Liu, Y.; Lloyd, A. W.; Mata, R. A.; May, A. J.; McNicholas, S. J.; Meyer, W.; Mura, M. E.; Nicklass, A.; O'Neill, D. P.; Palmieri, P.; Plüger, K.; Pitzer, R.; Reiher, M.; Shiozaki, T.; Stoll, H.; Stone, A. J.; Tarroni, R.; Thorsteinsson, T. ; Wang, M.; Wolf, A. MOLPRO, version 2010.1, a package of ab initio programs.

(53) Helgaker, T.; Klopper, W.; Koch, H.; Noga, J. J. Chem. Phys. 1997, 106, 9639-9646.

(54) Halkier, A.; Helgaker, T.; Jørgensen, P.; Klopper, W.; Koch, H.; Olsen, J.; Wilson, A. K. Chem. Phys. Lett. 1998, 286, 243-252.

(55) Ziegler, T.; Rauk, A. Theor. Chim. Acta, 1977, 46, 1-10.

(56) Morokuma, K.; J.Chem. Phys. 1971, 55, 1236-1244.

(57) Mitoraj, M.; Michalak A. J. Mol. Model. 2007, 13, 347-355. 
(58) Michalak, A.; Mitoraj, M.; Ziegler T. J. Phys. Chem. A 2008, 112, 1933-1939.

(59) Michalak, A.; Mitoraj, M.; Ziegler T. J.Chem.Theor.Comput. 2009, 5, 962-975.

(60) Becke, A.D. Phys. Rev. A 1988, 38, 3098-3100.

(61) Perdew, J. P. Phys. Rev. B 198633 8822-8824.

(62) Grimme, S.; Anthony, J.; Ehrlich, S.; Krieg, H. J. Chem. Phys. 2010, 132, 154104.

(63) ADF2014, SCM, Theoretical Chemistry, Vrije Universiteit, Amsterdam, The Netherlands, http://www.scm.com.

(64) te Velde, G.; Bickelhaupt, F. M.; Baerends, E. J.; Fonseca Guerra, C.; Van Gisbergen, S. J. A.; Snijders, J. G.; Ziegler, T. Chemistry with Adf. J. Comput. Chem. 2001, 22, 931-967.

(65) Fonseca Guerra, C.; Snijders, J. G.; te Velde, G.; Baerends, E. J. Towards an Order-N Dft Method. Theor. Chem. Acc. 1998, 99, 391- 403.

(66) To evaluate how short is the O...O distance (2.57 $\AA$ in average) in the free organic molecules containing the analyzed fragment we have found that this value is very similar to the O...O distances in transition metal complexes ( $2.59 \AA$ in average) where the oxygen atoms of the fragment coordinate to a metal ion and form five-membered chelate ring (Figures S3a and S4).

(67) Hansen, N. K.; Coppens, P. Acta Crystallogr., Sect. A: Cryst. Phys., Diffr., Theor. Gen. Crystallogr. 1978, 34, 909-921.

(68) Grabowski, S. J. (Ed.). Hydrogen bonding: new insights. Dordrecht: Springer, 2006.

(69) Kanny, P.W. J. Chem. Inf. Model. 2009, 49, 1234-1244 
(70) Stomberg, R. Lundquist, K. Nord.Pulp Pap.Res.J. 1994, 9, 37-43.

(71) Dange, N. S.; Hong, B. C.; Lee, G. H. RSC Advances, 2014, 4, 59706-59715.

(72) Cho, D. W.; Parthasarathi, R.; Pimentel, A. S.; Maestas, G. D.; Park, H. J.; Yoon, U. C; Dunaway-Mariano, D.; Gnanakaran, S; Langan, P.; Mariano, P. S. J. Org. Chem. 2010, 75, 6549-6562.

(73) Zbačnik, M.; Vitković, M.; Vulić, V.; Nogalo, I.; Cinčić, D. Cryst. Growth Des. 2016, 16, 6381-6389.

(74) Zbačnik, M.; Pajski, M.; Stilinović, V.; Vitković, M.; Cinčić, D. CrystEngComm, 2017, 19, $5576-5582$.

(75) Carletta, A.; Spinelli, F.; d'Agostino, S.; Ventura, B.; Chierotti, M. R.; Gobetto, R.; Wouters, J.; Grepioni, F. Chem. Eur. J. 2017, 23, 5317-5329. 
For Table of Contents Use Only

\title{
Short intramolecular O...O contact in some $o$-dialkoxybenzene derivatives generates efficient hydrogen bonding acceptor area
}

\author{
Goran A. Bogdanović, Bojana D. Ostojić, Sladjana B. Novaković
}

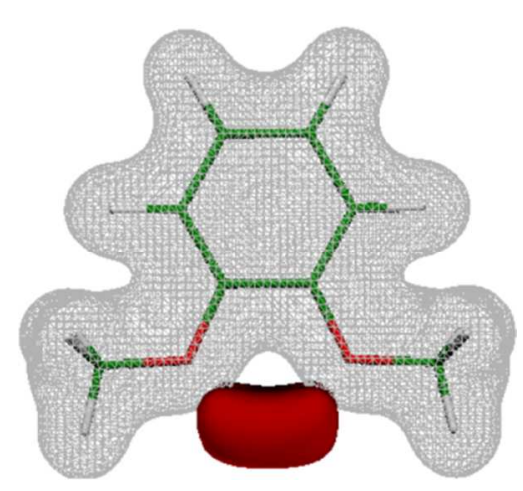

CSD analysis reveals highly predictable structural features of the $o$-dialkoxybenzene fragment comprising two ether oxygen acceptors in ortho positions of benzene ring. The consistence in fragment conformation leads to a predictable shape, spatial distribution and magnitude of the negative electrostatic potential and thus to a predictable interaction of the system in different crystalline environments. 